\title{
Conventional upper gastrointestinal endoscope retroflexion method for emergent biliary drainage in a patient with esophageal stricture
}

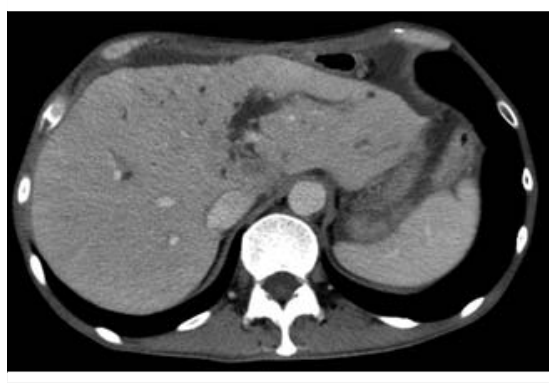

> Fig. 1 Contrast-enhanced computed tomography showed intrahepatic bile duct dilatation due to liver metastases with marked ascites.

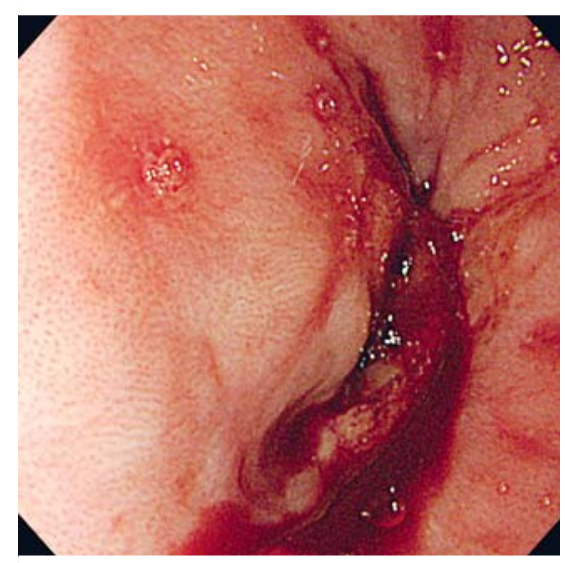

- Fig. 2 Endoscopic view of a malignant esophageal stricture.

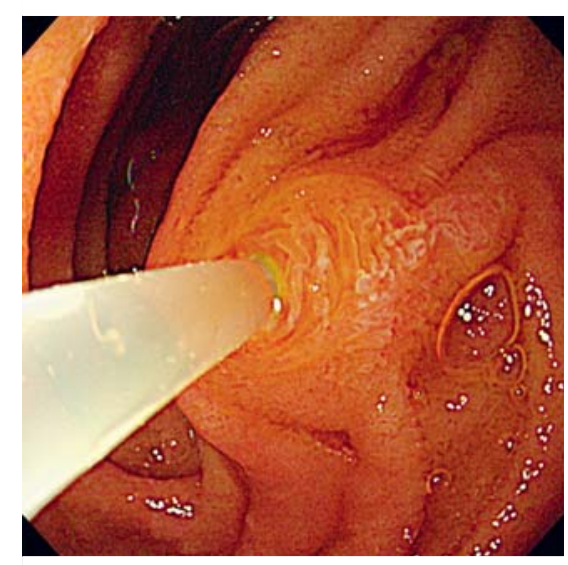

Fig. 3 Cannulation of the bile duct was achieved by retroflexing the scope in the second portion of the duodenum.
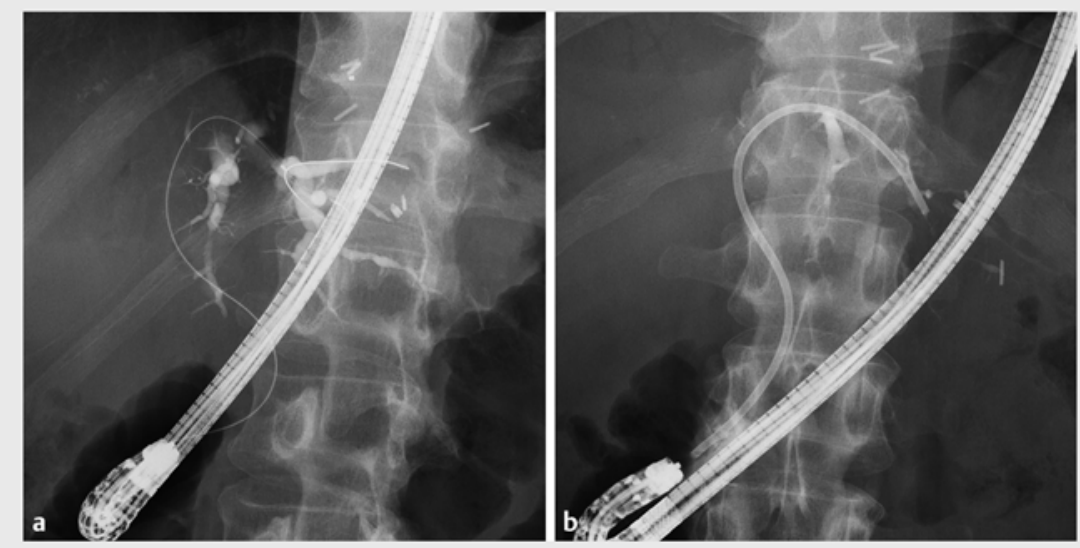

- Fig. 4 a Endoscopic retrograde cholangiography was performed in the retroflexed scope position. b A 7-Fr, 15-cm straight stent was successfully placed.
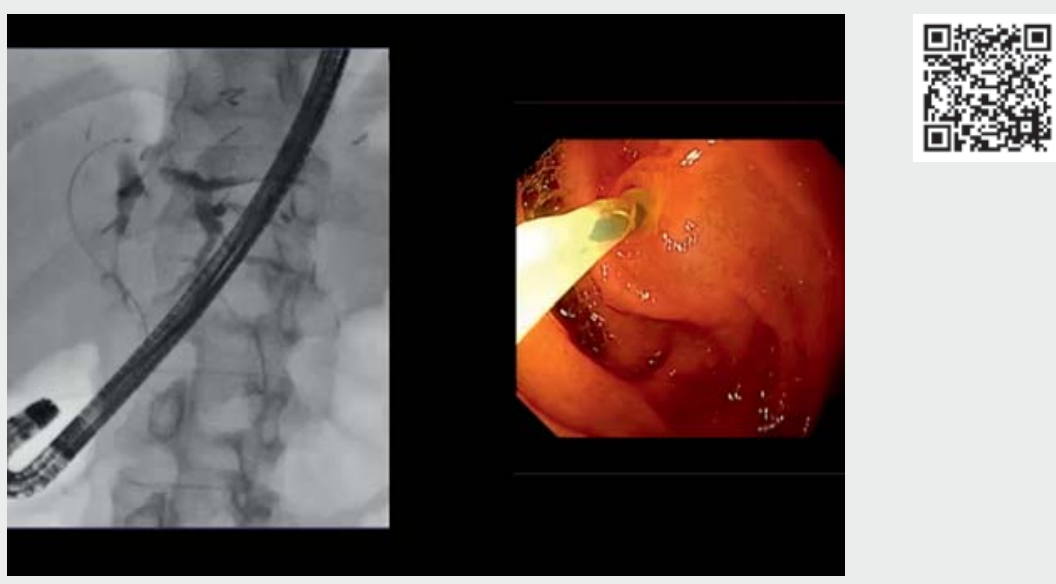

$\checkmark$ Video 1 Emergent endoscopic biliary stenting was performed using a conventional upper gastrointestinal endoscope.

Endoscopic ultrasound-guided biliary drainage (EUS-BD) is being increasingly used as an alternative treatment to percutaneous transhepatic biliary drainage (PTBD) for biliary obstruction in patients in whom transpapillary drainage fails or for whom this intervention is unsuitable [1-3]. Although endoscopic ultrasoundguided intrahepatic bile duct fistulation from a reconstructed gastric tube has recently been reported [4], EUS-BD cannot be performed in patients who have problems with ultrasound endoscope passage in the esophagus. Here we report successful performance of emergent endoscopic transpapillary biliary drainage using a conventional upper gastrointestinal endoscope.

A 53-year-old man who underwent esophageal cancer surgery with gastric 
tube reconstruction presented 15 months later with obstructive jaundice and acute severe cholangitis. Contrastenhanced computed tomography showed intrahepatic bile duct dilatation due to liver metastases with marked ascites (\$Fig. 1). We opted to perform emergent endoscopic transpapillary biliary drainage. However, a malignant esophageal stricture was unfortunately identified, and a side-viewing duodenoscope (JF-260V; Olympus Medical Systems, Tokyo, Japan) could not pass through the stricture ( $\mathbf{F i g} . \mathbf{2}$ ). We therefore attempted biliary drainage using a thinner conventional upper gastrointestinal endoscope (GIF-H290; Olympus Medical Systems, Tokyo, Japan). The scope passed through the stricture, and cannulation of the bile duct was achieved by retroflexing the scope in the second portion of the duodenum (-Fig.3). Finally, a 7-Fr, 15-cm straight stent (Flexima; Boston Scientific, Tokyo, Japan) was successfully placed, and adequate biliary drainage was attained ( $\triangleright$ Fig. 4 ; $\triangleright$ Video 1 ).

In this case, EUS-BD was impossible due to the esophageal stricture, and PTBD was inappropriate due to the marked ascites; on the other hand, once the scope passed through the stenosis, transpapillary biliary drainage seemed to be quite reasonable. Transpapillary biliary drainage using a conventional upper gastrointestinal endoscope requires no specialized equipment. This method is worth a try when confronting an esophageal stricture.

Endoscopy_UCTN_Code_TTT_1AR_2AZ
Competing interests

The authors declare that they have no conflict of interest.

\section{The authors}

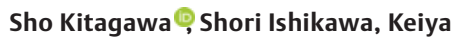 Okamura}

Department of Gastroenterology, Sapporo Kosei General Hospital, Sapporo, Japan

\section{Corresponding author}

\section{Sho Kitagawa, MD}

Department of Gastroenterology, Sapporo Kosei General Hospital, Kita 3 Higashi 8, Chuo-ku, Sapporo 060-0033, Japan bossa0405@yahoo.co.jp

\section{References}

[1] Sharaiha RZ, Khan MA, Kamal F et al. Efficacy and safety of EUS-guided biliary drainage in comparison with percutaneous biliary drainage when ERCP fails: a systematic review and meta-analysis. Gastrointest Endosc 2017; 85: 904-914

[2] Liao WC, Angsuwatcharakon P, Isayama H et al. International consensus recommendations for difficult biliary access. Gastrointest Endosc 2017; 85: 295-304

[3] Jovani M, Ichkhanian Y, Vosoughi K et al. EUS-guided biliary drainage for postsurgical anatomy. Endosc Ultrasound 2019; 8: S57S66

[4] Maehara K, Hijioka S, Saito Y. Endoscopic ultrasound-guided hepatico-gastrictubestomy for bile duct stent obstruction in a patient with recurrent cancer after esophageal cancer surgery with gastric tube reconstruction. Dig Endosc 2021; 33: 466-467
Bibliography

Endoscopy 2022; 54: E394-E395

DOI 10.1055/a-1550-2360

ISSN 0013-726X

published online 27.8.2021

(c) 2021. Thieme. All rights reserved.

Georg Thieme Verlag KG, Rüdigerstraße 14,

70469 Stuttgart, Germany

\section{ENDOSCOPY E-VIDEOS}

https:/|eref.thieme.de/e-videos

口血回 Endoscopy E-Videos is an open access online section, 靣解: reporting on interesting cases and new techniques in gastroenterological endoscopy. All papers include a high quality video and all contributions are freely accessible online. Processing charges apply (currently EUR 375), discounts and wavers acc. to HINARI are available.

This section has its own submission website at https://mc.manuscriptcentral.com/e-videos 